\title{
Professionalization as a governance strategy for synthetic biology
}

\author{
Lorna Weir · Michael J. Selgelid
}

Received: 3 June 2009/Revised: 20 July 2009/ Accepted: 27 July 2009

(c) The Author(s) 2009. This article is published with open access at Springerlink.com

\begin{abstract}
This article considers professionalization as a governance strategy for synthetic biology, reporting on social science interviews done with scientists, science journal editors, members of science advisory boards and authors of nongovernmental policy reports on synthetic biology. After summarizing their observations about the potential advantages and disadvantages of the professionalization of synthetic biology, we analyze professionalization as a strategy that overcomes dichotomies found in the current debates about synthetic biology governance, specifically "top down" versus "bottom up" governance and scientific fact versus public values. Professionalization combines community and state, fact and value. Like all governance options, professionalization has limitations, particularly regarding war and peace. It is best conceptualized as potentially part of a wider range of governance mechanisms working in concert: a "web of prevention".
\end{abstract}

Keywords Synthetic biology · Governance ·

Professionalization $\cdot$ Web of prevention · Dual-use

All research reported in the present article has been compliant with the conditions stipulated in the ethics reviews done by the Human Review Committee, York University, Toronto, Canada, and the Human Research Ethics Committee, The Australian National University, Canberra, Australia.

L. Weir $(\square)$

Department of Sociology, York University, Toronto,

ON M3J 1P3, Canada

e-mail: 1weir@yorku.ca

M. J. Selgelid

Centre for Applied Philosophy and Public Ethics (CAPPE),

National Centre for Biosecurity, The Australian National

University, Canberra, Australia
The emergence of synthetic biology has resulted in controversy over the governance structures of the life sciences, particularly genetic and genomic research. A number of governance methods have been debated with the aim to harmonize the development of synthetic biology with objectives variously posed as human health, national security, environmental safety, scientific freedom/progress, and economic growth. Proposals for synthetic biology governance have, inter alia, called for (new) codes of conduct for scientists, increased education of scientists regarding social and ethical implications of science, improved biosafety standards, security reviews of experiments and publications, governmental oversight of experiments and publications, restrictions on the selling of dangerous pathogens (called Select Agents in the USA) and/or potentially dangerous DNA sequences, registration of DNA synthesizers and other relevant technology, licensing and/or security-screening of those working with such technology, and strengthening of the Biological and Toxin Weapons Convention (e.g., to include verification mechanisms). Synthetic biologists and other life scientists have throughout these governance discussions consistently emphasized the need for initiatives that sustain the dynamism of science through open inquiry and international collaborations (Institute of Medicine and National Research Council 2006).

In this article we call attention to professionalization as a governance strategy for synthetic biology, one that has received mention but no real discussion in the literature. The topic of professionalizing synthetic biology arose during research interviews for our social science project investigating synthetic biology and biosecurity. In these interviews life scientists, editors of science journals, and the authors of US policy reports on synthetic biology remarked favourably and unfavourably about the potential 
advantages and disadvantages of professionalizing synthetic biology. We report this finding from researchin-progress so that it may broaden the ongoing governance discussions with respect to synthetic biology.

In most jurisdictions a profession is a legally mandated association granted a monopoly over specialized practices, a delimited authority delegated by sovereign states. Professional organizations require statutory legislation that constitutes colleges with broad powers. The officers of the colleges are elected by members of the college and are expected to become advocates for the profession. All professional practitioners are licensed and belong to an association/college which sets standards of practice for its members. To be licensed a practitioner must undergo education and training required by the college and, increasingly, ongoing education. The registrars of colleges license practitioners and may also initiate hearings into the professional conduct of licensed practitioners, hearings that may order anything from dismissal of the charges to delicensing of the practitioner. The legal structure and powers granted a profession are intended to align expert practices with the public good. We do not herein discuss those professional societies that are not authorized by statutory law and which have no licensing requirements. These function primarily as advocacy organizations and do not have the organizational capacity to mediate between specialized expertise and public values in the manner of the professional organizations mandated by statutory law that we discuss here.

Professionalization as an option for synthetic biology governance bypasses the simplistic dichotomy of "bottom up" and "top down" governance. It links the benefits of flexible self-governance to a public policy and legal framework. We argue that one of the strengths of professionalization as a mode of governance lies in its ability to bridge between science and public values. Although we do not take a position for or against professionalization, we do hold that expanding the range of available governance strategies is urgently needed. Professionalization would need to be coordinated with other forms of governance to operate effectively, including distinctively sovereign, political interventions related to, for instance, international biochemical weapons treaties.

This article reports on research in progress in a project investigating governance models for synthetic biology in relation to biosecurity. An initial set of 14 key informant interviews, one by telephone and 13 in person usually at participants' places of work, took place during February and June 2008. Lasting 60-150 min, the interviews were recorded and later transcribed. Research participants' personal identities are anonymized here, though some waived confidentiality. The following groups were purposively sampled: (1) synthetic and molecular biologists; contributors to the policy debate, including authors of governmental and nongovernmental reports on synthetic biology governance. The two classical molecular biologists in the sample had performed what subsequently came to be regarded as experiments of concern discussed in the governance literature on synthetic biology. The participants were drawn from the following areas of scientific, governmental and nongovernmental practice, with overlapping memberships so that the total exceeds 14: nine research participants are practicing synthetic biologists (7) and classical molecular biologists (2); two are editors of journals that published experiments of concern; two are members of the US National Science Advisory Board for Biosecurity (NSABB); one had been on the Fink Committee; two are authors of nongovernmental reports on synthetic biology; one is a member of a civil society organization, and one a bioethicist.

Our research participants were treated as key informants, meaning "people who are particularly knowledgeable about the inquiry and articulate about their knowledge" (Patton 2002, p. 321). This approach to research interviewing provides a means of documenting interpretations, reflections, histories, and motivations that do not appear in written articles and reports where authors must speak on record and authoritatively. Because qualitative research such as this does not use the kind of sampling used in quantitative studies, our data does not permit generalizing about how many or what proportion of synthetic biologists support professionalization. Rather than statistical analysis, the purpose of this article is to report and analyze what was said about professionalization by a number of highly knowledgeable people who have participated in the debate about synthetic biology governance. This finding is of interest because the professionalization of synthetic biology has not previously received substantial published discussion.

\section{Professionalizing synthetic biology: making scientists think like doctors}

Professionalization may be seen as a strategy for making scientists think and act like doctors. Participants in our study represented science as a discovery-oriented, amoral pursuit of knowledge, while the professions, particularly medicine, were understood to link expert knowledge with moral obligation. One participant commented: "[t]here was this conversation in the Fink Committee about, well, scientists don't think like doctors. And physicians have this is the argument - [a] well worked out understanding of their moral obligations, their fiduciary duties as professionals and so on. Scientists have one overriding value, and that is the ... pursuit of new knowledge" 
( $\mathrm{RP}^{1}$ 04). Another participant, a physician-scientist, also posed the distinction between science and the professions in moral terms, contrasting medical students with graduate students in the sciences. Medical students, the participant observed, have a deep sense of doing no harm to patients whereas, in scientific experiments, "[t]he graduate students don't get it just yet. They don't stop to think about what's the potential impact of this particular set of experiments. They just don't. And I don't even yet" (RP 01).

Some research participants viewed professionalization as a way of rendering synthetic biology compatible with public health, national security, and public accountability. Others doubted that professionalization would have any effect on national security and environmental safety. A journal editor and scientist argued that the life sciences have only now reached a stage of industrialization that chemical engineering attained decades ago:

This is really new stuff for life scientists. Engineers have been doing these kinds of things which affect populations for a very long period of time... I would not consider that [professionalization] ${ }^{2}$ to be intrusive to the conduct of research. I would think it would be a recognition of what this research means to society (RP 02).

Another scientist suggested that making synthetic biology into a profession would "be relevant to biosecurity" because a profession could "establish standards of practice and then hold people accountable to them" (RP 10). A bioethicist was skeptical that professionalization would have any national security or environmental benefits, asking what is the problem to which professionalization might be the solution:

You need a map of what are the concerns and worries. And what are the cultural and institutional responses that make the most sense for a particular worry. So I'm not sure, for example, that increased professionalization is a very efficient or ... a very effective response to, say, a worry about dual use or a worry about environmental hazards. Professionalization understood simply to be that there's a recognition that you have a kind of accountability as a profession to society. You could go a long way in that direction (RP 04).

This research participant treats professionalization as an ineffective response to biosecurity and environmental questions, but an appropriate one if the intent is to render synthetic biology publicly accountable.

\footnotetext{
1 "RP" is an abbreviation for "research participant".

${ }^{2}$ Square brackets indicate additional words inserted for clarification.
}

In synthetic biology today certain scientists do "think like doctors": engineers. Synthetic biology integrates engineering, which is already organized as a profession, with the life sciences, which are not. As one scientist observed, "[o]ne of the most interesting things happening in synthetic biology is that there are engineers of all sorts swarming into biology and that is a different culture than a scientific culture" (RP 10). This participant differentiated the life sciences from engineering in their cultural orientations, science being about "discovery and understanding and curiosity", whereas in engineering "we try and make stuff based on limited understanding and limited resources and limited abilities to manipulate the physical world" (RP 10).

Unlike synthetic biologists trained primarily in the life sciences, those synthetic biologists educated as engineers are familiar with professional societies because engineering has been organized as a profession in most EuroAmerican jurisdictions since the nineteenth century. Their familiarity with engineering led them to suggest a series of analogies between the engineering profession and the future governance of synthetic biology. As the anthropologist Strathern (1992, p. 152) has demonstrated, analogy operates as a form of borrowing between discrete domains of social practice, "a conserving exercise in so far as new entities or ways of thinking are built up through already existing ones." Synthetic biologists from an engineering background are accustomed to licensing and their work being subject to oversight. Professions have the legal authority to develop standards of practice, and failure to abide by the professional standard of practice may jeopardize a practitioner's license. Engineers sign their work, rendering them at least potentially liable if it should be defective. This professional system of incentives and penalties is not found in the life sciences, but can be extended by analogy to them.

Bridge building is an example that study participants repeatedly used to explain the effects of professionalization on engineering practices. Engineers, one participant noted, are licensed and will "be held accountable when the bridge falls down" (RP 10). By analogy, if synthetic biology were to become a profession, its practitioners would become accountable for their work: their bridges would have to stand up. However, another participant rejected bridge building as a model for biological research:

[I]t's important for them to recognize - the engineering side of the world - that ... in the biological world it's a different kind of research outcome than building a bridge where you have a certain set of rigorous standards within which you have to operate such that the bridge doesn't fall down. It's not just a "Hey! Let's see what we can build" kind of thing" (RP 01). 
As a physician who repeatedly called attention to the limits of medicine in therapeutic practice, it was counterintuitive for this participant to consider him/herself a bridge builder. Using engineering as a governance model for synthetic biology gives rise to a series of partial and contested analogies.

One scientist argued that professional licensing would be appropriate for synthetic biologists working on projects that involve environmental release of synthetic organisms, though not for basic research conducted in laboratories that would have no environmental release. All synthetic organisms released outside the laboratory, it was suggested, should be 'signed' in a fashion analogous to the way engineers currently sign their work: "[What] I'd like to see would be a professional standard of practice that genetic engineers sign their work and that translates practically into things being embedded into the DNA itself. These standards would include standards for detection within the environment and also attribution" (RP 10). On analogy with engineering, "signing" synthetic organisms would involve DNA insertions that could be linked to a code that would personally identify scientists. A second participant linked "signing" organisms with cultural differences between engineers and biologists, again using the bridge building analogy:

One of the cultural differences between engineers and biologists is that - and actually I still have trouble with whether this is literally true - engineers sign their works. If a bridge falls down, presumably you know where that bridge came from, because there's a paper trail saying, "You people are responsible." The parallel that people try to make is with someone who makes a pathogen. There's no signature there, and you don't know who's done that (RP 11).

One scientist questioned the appropriateness of any environmental release, signed or otherwise, of synthetic and genetically modified organisms that would involve animals: "[a] virus that is released ...into an environmental area where there are animals that you can't bring back or control, that would have to be a concern. That is never actually addressed at government or gene regulatory authority or anything like that" (RP 13). The idea that "signing" is a solution is here contested on ecological grounds.

Professions commonly have a code of ethics that acts as a statement of the fundamental goals-or "calling"-of the profession and as a normative guide for practitioners. Codes of ethics differ from the "codes of conduct" that have been more widely discussed as a governance option for synthetic biology (Garfinkel et al. 2007; Mauer et al. 2006) as they appear in a professional context rather than being stand-alone documents. Professional codes of ethics are incorporated in practitioner education and they may also be used in disciplinary hearings before a college's registrar or in courts of law-for example, when plaintiffs make charges of "negligence" because "standards of practice" have not been met.

One participant objected to professionalization as a governance strategy, arguing that scientists would not in principle be able to conform to codes of ethics:

This question of a license: I go in and then I have to pass an examination, like an MD. And then I'm allowed to do research. And there is a code of ethics and it says: "You do not produce anything that can do harm to somebody". The problem is, in research, you don't really know when you do an experiment what the outcome is. You don't really know if, in five years, it could be a horrible result, like the mousepox virus. The people who put this together, they had no inkling that this could be a virus that would kill vaccinated animals (RP 05).

We note that some codes are currently drafted to oblige members to make an effort to identify reasonably foreseeable outcomes before starting work and to take outcomes into account when planning, conducting and reporting research (Green et al. 2006).

A physician research participant said that codes of conduct "have absolutely no influence over somebody intent on doing the wrong thing. No question about it" (RP 01). But in the case of medicine, the code of ethics that "we give to our medical students when they get their lab coat on the first day of school and the code of conduct we say at graduation four or six years later... gets so ingrained in our medical students" (RP 01). Ethics modules are compulsory parts of medical education, integrated into it from the first day of medical school.

\section{Analytic observations}

From these remarks of our research participants, a number of analytic points may be drawn about professionalization as a governance strategy for synthetic biology. First, professionalization breaks with the strong polarization between science-community-based and state-based regulation that has characterized so much discussion about the governance of synthetic biology. Professional organization contains elements of both self-governance and legally-authorized, politically mandated governance, what people informally today term "bottom up" versus "top down" governance. The powers of college registrars to investigate claims against practitioners, order remediation, and delicense practitioners illustrate the top down side of professional governance. The combination of legislated mandate and collegial self-governance provides a flexible mechanism of professional 
accountability for a profession as a whole and for its individual practitioners. Second, professionalization is a strategy for constructing the synthetic biologist as a responsible subject. This would extend and formalize already existing community discussion about integrating scientific practice with ethical and social obligations. A profession defines the fiduciary responsibilities of practitioners to clients and of the profession to public good. It assures adequate educational standards for its practitioners both at the point of licensing and through educational programmes after licensing. Professions act to create competent practitioners and to deal with incompetent ones. By these means professions socially demonstrate that their practitioners are adhering to the ethical obligations with which they have been entrusted. Third, professionalization is linked to the formation of an ethos. By ethos we mean the sense of attachment and commitment that persons feel to the groups of which they form part (Bendix 1960, pp. 260-261). The formation of a professional ethos for synthetic biology would involve the emergence of a distinctive way of thinking and feeling for members of that profession. The professional ethos would also orient synthetic biologists to their work as an ongoing ethical task. ${ }^{3}$

Our fourth analytic point is that professionalization provides a means of addressing one of the fundamental dilemmas in present governance discussion about synthetic biology: the linking of fact and value without damaging the conduct of scientific research. Almost a century ago Max Weber (one of the founding figures of sociology), in a famous paper entitled "Science as Vocation" (Wissenschaft als Beruf; Weber 1958 [1922]), argued that science is a type of formal, value-free rationality. Formal rationality is one way of integrating the goals of human action with the means used to attain these goals. It analyses the means and calculates the relation between means and goals, but takes the goals of action as given. As a type of formal rationality, science does not reason about the goals of its practices and cannot give answers about what it should do. In Weber's (1958, p. 144) words: "Natural science gives us an answer to the question of what we must do if we wish to master life technically. It leaves quite aside, or assumes for its purposes, whether we should and do wish to master life technically and whether it makes sense to do so." ${ }^{4}$ When values are conceived as coming to

\footnotetext{
${ }^{3}$ For a discussion of ethos see Foucault (1997, p. 309).

${ }^{4}$ Since the publication of Weber's "Vocation of Science" in 1922, much has changed in science. After the bombing of Hiroshima and Nagasaki, some scientists became public intellectuals and took on advocacy for nuclear non-proliferation. Later Rachel Carson's Silent Spring (1962) initiated a new role for scientists qua scientists taking positions on ecological matters such as climate change, damage to the world's oceans, and the destruction of plant and animal species. These are instances of scientists taking substantive value positions in a way not anticipated by Weber.
}

science from without, scientific knowledge is confronted with a number of paradoxes. For instance, Weber argues, the assumption that scientific knowledge is worth knowing is actually a statement of value that science cannot prove. Nor can the value of the technical mastery of life be established through scientific reasoning. Scientific knowledge, moreover, is incapable of arbitrating conflicting value commitments. In principle synthetic biology, like any science, cannot itself establish a conception of the good society and what the place of science in such a society ought to be.

One of the merits of professionalization as a governance strategy for synthetic biology lies in its capacity to articulate the formal, amoral reasoning of science with normative professional standards and substantive values. Professionalization would have the effect of opening a space of accountability under a legislative mandate that established a college of synthetic biologists. A professionalized synthetic biology would provide a practical context for devising and enforcing standards of practice and codes of ethics.

It would be naïve to think that professions inevitably align with the public good. Fiduciary responsibilities to clients and the public are counterbalanced by promoting the benefit of the profession and the individual practitioner. Professions are inherently fields of normative conflict between the interests of the profession, the interests of the practitioner, and the public good. Professional practitioners tend to deal with incompetent practitioners by forming internal referral networks to protect their clients, that is, through evasion rather than report to the college registrar. In addition, professional organization creates stratification among forms of expert labour, with professions ranked at the top. How this would affect the place of synthetic biology among the life sciences is presently unknown. Professionalization is no panacea for the governance challenges facing synthetic biology today.

\section{Professionalization in a web of prevention}

Professionalization may gain popularity among synthetic biologists if social and ultimately political sentiment proves unwilling to tolerate a completely "bottom up", voluntary approach to synthetic biology governance given the apparent biosafety and biosecurity risks associated with this area of science and technology. If they were given the choice between professionalization and regulation by government, synthetic biologists would likely prefer the former, as this would appear to protect a greater measure of scientific autonomy.

Even if professionalization takes place, this would not mean that there would then be no need for governmental 
regulation whatsoever. Just as the choice between "bottom up" and "top down" governance amounts to a false dichotomy, so may the choice between professionalization and a "top down" regime. The professionalization of medicine, by analogy, has not meant that doctors have only the medical profession to answer to. Governmental bodies also play a major role in the regulation of medicine. In the US, for example, FDA approval is required for the licensing and marketing of drugs - and abortion is only permitted because the Supreme Court ruled that state prohibitions against it would be unconstitutional given the right to privacy. Substantial control over medicine is also held by other institutions such as private insurance companies, particularly in those jurisdictions with limited or non-existent stateprovided health care. In the context of medicine, professionalization is an important part of governance-but it is not the whole story. The same arguably would, and should, be true in the context of synthetic biology.

One of the major societal concerns about synthetic biology is the dual-use nature of this kind of science and technology. Techniques used to design new organisms or re-design existing ones may have numerous significant benefits for humankind. But the same techniques might be used by malevolent actors in the production and use of biological weapons that pose serious threats to human health and security. Since all synthetic biology techniques may be argued to be inherently dual use, the boundary between what is of concern to the public good and what is not poses great conceptual difficulties.

The protection of security is usually considered to be a key role of government (Miller and Selgelid 2008), and it would thus be surprising-and perhaps imprudent-for governments to leave all (relevant) control over security in the hands of the synthetic biology profession itself (Selgelid 2007). Some degree of government oversight not mediated through professional societies will be necessary. Under the UN Security Council Resolution 1540 all sovereign states have the legally binding obligation to ensure that nuclear, chemical or biological weapons are not developed, acquired or used inside their territories by nonstate actors (United Nations Security Council Resolution 1540 2004). It can be expected that professional organization would exert some control over unlicensed hackers and amateurs, but it would not be capable of completely preventing research, development and deliberate use of synthesized pathogens. The question of bioweapons is a largely a matter of international law and state sovereignty, not merely a matter of professional regulation.

The upshot of this discussion is that it would be mistaken to think that professionalization of synthetic biology, whatever its merits, would be a magic bullet for solving biosecurity issues. A growing consensus in the literature on the dual-use phenomenon and biological weapons prevention holds that a complex "web of prevention" is needed for the protection of biosecurity (Rappert and McLeish 2007; Dando 2008). Rather than choosing between the various governance options listed at the beginning of this paper and/or professionalization, biosecurity may require reliance on (elements of) many governance modes acting in synergistic combination. Professionalization of synthetic biology could be a good thing-but some degree of governmental oversight, the strengthening of relevant weapons conventions, regulation of trade/transfer, and possession and use of dual-use materials and technology will still be necessary.

\section{Conclusion}

This article has summarized the reflections on professionalization that our research participants made in the context of a project still in progress. We have analyzed professionalization as a governance form that overcomes some of the polarities found in current debates about synthetic biology governance, in particular top down versus bottom up governance and scientific fact versus public values. Professionalization combines community and state, fact and value. However, professional organization does not supersede the polarity around bottom up and top down governance, which continues to represent significant positions in a social and political debate. We have also argued that professionalization ought to be conceptualized as part of a wider range of governance mechanisms working in concert, but that professionalization has at most an ancillary role to play in questions of war and peace. Professions do not sign international bioweapons conventions or treaties providing global, post-national mechanisms for dealing with international public health emergencies that would result from accidental or deliberate bioweapons use (Weir and Mykhalovskiy 2009). Like all governance options, professionalization has limitations.

The beginnings of synthetic biology occurred in the USA. It first became visible to those outside the small number of its practitioners in the post-9/11 political landscape. Early discussions of synthetic biology governance thus took place amidst the security agenda of the Bush administration. Under these conditions, scientists rallied to defend scientific research, publishing, and international collaborations against measures being contemplated in the name of security. The end of the Bush years may create the conditions for less defensive participation by scientists in discussions about synthetic biology governance. Perhaps it is the creation of ongoing spaces of reflection and debate that are most needed now, as a scientist remarked to us: "Given the fact that the underlying technologies are changing so dramatically..., it becomes unbelievably 
important to me to imagine and take steps to put in place mechanisms that support dialogue, both in terms of governance, bottom up and top down, but also in terms of ethical issues ... Long-term persistent constructive discussion seems critical" (RP 10).

Acknowledgements The qualitative research presented in this article was funded by the Social Sciences and Humanities Research Council (SSHRC) of Canada, as part of a project on "Biosecurity and Synthetic Biology", with Lorna Weir as Principal Investigator and Michael J. Selgelid as International Collaborator. Additional support was provided by the Vice President of Research and Innovation and the Dean of Arts, York University (Toronto) and the National Centre for Biosecurity and the Centre for Applied Philosophy and Public Ethics (CAPPE) of the Australian National University. The production of this article was also partly supported by a Wellcome Trust Enhancement Award in Biomedical Ethics- "Building a Sustainable Capacity in Dual-Use Bioethics" (Chief Investigators: Malcolm Dando, Simon Whitby, Jim Whitman, Brian Rappert, Judi Sture, and Michael Selgelid). We thank all those who consented to be interviewed for their participation in our research.

Open Access This article is distributed under the terms of the Creative Commons Attribution Noncommercial License which permits any noncommercial use, distribution, and reproduction in any medium, provided the original author(s) and source are credited.

\section{References}

Bendix R (1977 [1960]) Max Weber: an intellectual portrait. University of California Press, Berkeley

Dando M (2008) Biosecurity: upgrading the web of prevention: a view from the UK. In: Symposium on biosecurity challenges for Australia and its region, National Centre for Biosecurity, The Australian National University, Canberra, 11 February 2007

Foucault M (1997) What is enlightenment? In: Rabinow P (series ed) Essential works of Foucault 1954-1984, Rabinow P (ed) Ethics, vol 1. The New Press, New York, pp 303-320
Garfinkel MS, Endy D, Epstein GS, Friedman RM (2007) Synthetic genomics: options for governance. JCVI, CSIS, MIT. http://www. jcvi.org/cms/fileadmin/site/research/projects/synthetic-genomicsreport/synthetic-genomics-report.pdf. Accessed 28 May 2008

Green SK, Taub S, Morin K, Higginson D, for the Council on Ethical And Judicial Affairs of the American Medical Association (2006) Guidelines to prevent malevolent use of biomedical research. Camb Q Healthc Ethics 15:432-447

Institute of Medicine, National Research Council (2006) Globalization, biosecurity, and the future of the life sciences. The National Academic Press, Washington

Mauer S, Lucas KV, Terrell S (2006) From understanding to action: community-based options for improving safety and security in synthetic biology. Goldman School of Public Policy, University of California, Berkeley. http://gspp.berkeley.edu/iths/UC\%20 White\%20Paper.pdf. Accessed 28 May 2008

Miller M, Selgelid MJ (2008) Ethical and philosophical consideration of the dual-use dilemma in the biological sciences. Springer, Dordrecht

Patton MQ (2002) Designing qualitative studies. In: Patton MQ (ed) Qualitative research and evaluation methods, 3rd edn. SAGE, Thousand Oaks, pp 209-258

Rappert B, McLeish C (2007) A web of prevention: biological weapons, life sciences and the future governance of research. Earthscan, London

Selgelid MJ (2007) A tale of two studies: ethics, bioterrorism, and the censorship of science. Hastings Cent Rep 37(3):35-43

Strathern M (1992) After nature: English kinship in the late twentieth century. Cambridge University Press, Cambridge

United Nations Security Council Resolution 1540 (2004) Non-proliferation of weapons of mass destruction. Available: http://daccessdds. un.org/doc/UNDOC/GEN/N04/328/43/PDF/N0432843.pdf?Open Element. Accessed 15 July 2009

Weber M (1958 [1922]) Science as vocation. In: Gerth H, Mills CW (eds) From Max Weber: essays in sociology. Oxford, New York, pp 129-156

Weir L, Mykhalovskiy E (2009) Global public health vigilance: creating a world on alert. Routledge, New York (forthcoming) 